\title{
East Enlargement and New Territorial Structure of European Union: What Advantages and Disadvantages for Balkan Countries?
}

\author{
Giacomo Cavuta, Dante Di Matteo* \\ Department of Economics (DEc), University “G. d'Annunzio”, Italy
}

Copyright (C) 2016 by authors, all rights reserved. Authors agree that this article remains permanently open access under the terms of the Creative Commons Attribution License 4.0 International License

\begin{abstract}
In a context just like the today's one it is necessary to give answers to some questions about the future scenarios that lie ahead in the light of the upcoming changes in the territorial structure of the European Union. The east enlargement is the last step of a harmonization process which started several years ago and which will also allow the Balkan countries to join the Community, if the minimum requirements and necessary conditions for membership are respected. At this point, the discussion items are numerous and include all the fundamental sectors of national economies: trade, agriculture, industry, tourism, labor market, social cohesion, environment, research and development, finance; for each of the above mentioned segments there are complexities, advantages and disadvantages that the incoming countries will have to face in order to gain admission into the EU. The aim of the paper is to identify those aspects such that each of the seven countries has or not convenience to take part of the European Community. Through the construction of a standard model that involves the most significant variables, it will be possible to identify what are the Eastern countries that possess the right and favorable conditions for membership.
\end{abstract}

Keywords Community, Enlargement, Geopolitics, Transformation

\section{Introduction}

In recent years have been produced profound transformations in the international economic order as a result of a clear trend towards interdependence of a supranational scale economic systems and a more pronounced polarization of the development and growth problems in conflict between North and South, East and West of the world. In particular, it is well evident the existence of strong disparities within the Community. It seems obvious that, in a system of close connections and political and economic correlations, a non-homogeneity and uniformity is a problem to solve. In order to combat the differences between the regions, the Community has moved in many directions with the help of different instruments.

The most important financial instrument of EU regional policy [1] has certainly been the European Regional Development Fund, with the introduction of two additional funds for the economically disadvantaged regions: the European Social Fund and the FEAOG-Orientation (intended to encourage the improvement of facilities and agriculture sectors of EU). In order to use the Structural Funds as effectively and efficiently as possible, it was decided to divide the poorest regions in subcategories to be able to highlight their peculiarities. In this way it was possible a more direct approach to the issues of the various regions. In particular, the FESR has been used in favor of the three groups of regions, each corresponding to a precise objective: regions lagging in development, regions in industrial decline, rural regions. Since the Community economic policies are implemented on the basis of these territorial subdivisions, it is good to try to understand under what considerations underlying these have been identified. The regions lagging in development [2] have been identified on the basis of the measurement of GDP per capita. They are generally defined as areas where the GDP per capita is less than $75 \%$ of the Community average. The regions that fall into this category are: Andalusia, Asturias, Castilla y Leon, Castilla-La Mancha, Cueta and Melilla, Valencia, Extramadura, Galicia, Canarias, Murcia, Corsica, Greece (whole country), Abruzzo, Basilicata, Calabria, Campania, Molise, Sardinia, Sicily, Northern Ireland, Portugal and Ireland (whole Country). All these areas are characterized by having a peripheral position, south and west of the Community. A quarter of the population of these areas live in the islands, some of which are very small (Greek Islands) and far away (Canary Islands, Azores, Madeira).

Considering the unemployment rate and GDP per capita we can distinguish regions lagging behind that in the ' $80 \mathrm{~s}$ had a favorable evolution and others, which have suffered a 
reverse trend. In this regard, Portugal and most of the areas in Spain can be defined converging, being characterized by an increase in GDP per capita faster than the average, and accompanied by an increased reduction in the unemployment rate. Similarly in Northern Ireland, in three Adriatic regions and in most other Spain regions, there has been a development of production higher than average, although its unemployment levels are somewhat deteriorated. Greece and the other Italian regions recorded a less favorable evolution and moved away from the EU average both in economic output and in terms of the labor market [3]. From this point of view, therefore, the regional development is rather contradictory and raises many ideas for a careful assessment of the distribution of these areas within the Community. We can't ignore the close relationship that exists between the marginal geographical location internal problems of income and employment.

The areas in industrial decline, those eligible under Objective 2, are densely populated (on average more than twice of EU average) with a density that in some cases is higher than 1000 inhabitants $/ \mathrm{km}^{2}$. It includes, therefore, areas that are facing serious problems of regional planning: problems of congestion, the abandonment of industrial settlements and pollution. In 1990 the unemployment rate [4] in Objective 2 was $1.2 \%$ higher than the EU average $(9.5 \%$ vs. $8.3 \%$ ), although significantly less than that of the regions lagging behind. The situation of these areas shows, moreover, considerable signs of improvement. The Community's rural areas cover more than four-fifths of its territory and account for about one third of its population. The same areas under Objective- $5 b$ represent $17 \%$ of the Community's territory, but only $5 \%$ of its population. The low density and the limited accessibility (insularity, remoteness from economic centers, mountain areas, etc.) represent disadvantages both for the development of modern agriculture, and for the establishment of new economic activities. These areas also includes some weaker areas in which - in the last 25 years has had a depopulation due to emigration that in many cases involved more than half the population. Among the sectors of potential development should be mentioned the tourism and crafts (both independent agricultural activity, but complementary to it) as well as the development of small and medium-sized local industries.

\section{Literature Review}

In the context of establishing the single market, as an initiative designed to contribute to increase the integration within the Community, the European Regional Development Fund and the Community regional policy, were expressly included for the first time in the treaties establishing the European Communities. These treaties [5], entered into force in 1989, have fundamentally changed both the structure and the objectives of the European Regional Development Fund. The aim of the reform, which involved all the structural funds was, on one side, to focus interventions on a limited number of priorities, in order to not waste the energy, and secondly, to establish a new approach regarding the implementation and management of the programs. For all Funds, the reform introduced a number of new elements:

- concentration of operations in favor of a limited number of clearly defined objectives, with particular emphasis on promoting the development of lagging regions;

- doubling the used resources compared to 1987 ;

- changes in management regarding the establishment of Community support frameworks and procedures relating to the monitoring of the implementation and evaluation of assistance;

- interventions through multi-annual programs rather than projects, to ensure better coherence and effectiveness of the actions taken;

- delegation of the Council powers to the Commission, to allow the launching of Community-based programs;

- closer coordination between the three Structural Funds and other financial instruments of the Community, so that the community frameworks could cover and coordinate the actions of all the financial instruments;

- $\quad$ significant strengthening of partnership by associating the regions and the programs implementation;

- use of many financial assistance types by the Community with greater flexibility regarding the granting of advances.

Regarding the FERS, the reform introduced other new elements [6]; in the first place, it has provided a greater concentration of its field of intervention, both from the operational point of view, and both from the geographical one. In particular, about $80 \%$ of the available budget was concentrated on Objective-1; second, the system of prior allocation fixed by Council $(85 \%)$ has been replaced by an indicative breakdown between the Member States about the use of the Fund established by the Commission, in order to facilitate the assistance planning. The regions and areas eligible under these objectives were determined on the basis of criteria and Community statistics thresholds, and in accordance with procedures established by the regulations on the Structural Funds. The areas covered by Objectives- 2 and $5 b$ have been outlined with a strictly geographical level in order to concentrate Community action on the worst hit areas in difficulty, small and isolated (Member States may include regions eligible under different objectives). In this sense, we can distinguish three groups: the first group consists of weaker states like Greece, Portugal and Ireland, which territories are entirely covered by Objective-1, affected by special problems of rural development or industrial restructuring; the second group includes Spain, France, Italy and the UK, countries where action is taken depending on the three regional objectives and in terms of population, in these four Member States the objectives affecting respectively $83 \%$ of the population in Spain, $48 \%$ in Italy, $40 \%$ in the UK and $30 \%$ in France; in the last group are placed those Member States that include all regions and other areas eligible under Objectives-2 and $5 b$. 
In the context of the support measures, which essentially take the form of operational programs, the FESR can financial investments of a very different nature: large communications infrastructures, water and energy supply, support structures for enterprise development (realization of industrial facilities services-related, business infrastructure, telecommunication services, protection measures for the environment, etc.) or investments in business-related services (consulting, research and development). In order to obtain an optimal impact, the resources have been concentrated on a limited number of priorities within each Community support framework. Taking into account the specific needs of each region, the Fund tried to achieve a balance between investment in infrastructure and those for the productive sector. The financial resources for the EU regional policy in 1990 reached 5.4 billion ECU, which 2.8 billion to finance new initiatives, while the remaining part was used for the works already in progress, slightly exceeding the $0.1 \%$ of the Community GDP. In particular, in less developed regions, the serious shortcomings in the economic infrastructure have suggested to dedicate to this sector about $60 \%$ of the total funds. Interventions of this kind have become particularly needed in Greece and in some regions of Spain and France, because of their extremely peripheral situation, their insularity or simply due to insufficient investment in the sector.

Simultaneously the emphasis was placed on funding designated to improving the productive sector in Portugal and in Italy, where spending has reached about $40 \%$ of expenditure from the Fund [7], the $30 \%$ of available appropriations. The rest of the expenditure of the FESR $(10 \%)$ went to support local actions that include a series of measures to stimulate regional economic development regarding business services (financial and non-financial), the promotion of entrepreneurship, the development of human resources and local tourism. If we consider jointly the three Structural Funds, only a third of the spending went to basic infrastructure and a quarter to the productive sector; another quarter covered the tourism, agriculture, rural development and human resources and the remaining fifth was used for horizontal measures (not regional). The spending percentage on basic infrastructure was significantly lower in Objective-2 areas, with only $16 \%$ of Regional Fund expenditure and covers only three Member States: Spain, UK and, more marginally, Belgium. Although the distinction between investment in production and infrastructure is not accurate, in Objective-2 there is a clear orientation towards a Community support, aimed to increase the competitiveness of the productive sector, especially regarding local initiatives.

The action the Community engaged through the Structural Funds was not limited to the measures outlined, but also includes a series of other initiatives that the Commission can promote, directly to:

- help to resolve serious problems related to the implementation of other Community policies;

- promote the application of Community policies at regional level;

- help to resolve common problems to some region categories.

While the Community support frameworks previously used was based on national development plans, these initiatives consist of transnational programs that privilege in equal measure - the involvement of regional and local authorities in the preparation and implementation phases. Community initiatives are the further implementation of two key principles of the reform: the sharing and complementarity. One of the main goals of EU regional policy is to ensure that businesses in less developed regions and those located in declining industrial regions can benefit from the advantages of the single internal market. The initiatives are mostly designed to promote a growth process that meets the needs of the single market and the increased competitiveness. As far as possible, the Community initiatives have been designed to contribute, at the regional level, the success of particular EU policies, whose effectiveness should be enhanced regarding the development of the most disadvantaged regions.

\subsection{The Macroeconomic Relevance of the EU Regional Policy}

The resources that the EU regional policy possesses after the aforementioned reforms offer new opportunities to the regions; it's possible to provide an indication of the importance of the structural funds and establish the conditions for successful intervention in the interested regions. The EU regional policy expenditure is reflected on the Member States development and their regions in two ways:

- by co-financing physical investments aimed at facilitating and promoting government investment and production, which are the main conditions for a lasting increase in employment, production and income;

- by transferring financial resources able to reduce balance of payments problems and allow - thanks to higher imports - a direct increase of available properties.

Regarding the first point, the contribution of EU regional policy to the financing of physical investment (economic infrastructure and productive investments) can be illustrated by the relationship between the cost of the FESR and the gross fixed capital formation (FCLF) in assisted regions. In 1989 the Regional Fund has financed the $0.5 \%$ of FCLF in the Community and more than 3\% was part of Objective-1 regions. In the most disadvantaged States (Ireland, Greece and Portugal) it has financed between $5 \%$ and $7 \%$ of total investments, while in the other Objective-1 regions, its contribution ranged from $2 \%$ to $3 \%$ of gross capital formation fixed. Considering the volume of available financing available for the less developed regions, sometimes it is argued that these may not always be able to absorb [8] these resources. If we consider the Community 
definitions of subsidized spending for investments and the maximum percentage of financial contribution $(75 \%$ for regions under Objective-1) there is a risk, at least theoretically, that a region can make insufficient investments and absorb available Community resources. In the remote possibility of an absorption problem, it's possible to remedy by expanding the definition of eligibility or increasing the rate of contribution borne by the regions.

These absorption problems may also derive from other factors, such as:

- administrative and organizational problems at national and regional level;

- inadequate levels of regional investment, particularly in infrastructure.

Problems related to the absorption of a greater volume of Community resources can generally be avoided when the Member States increase their eligible expenditure in the same amount of the Community. This leads to a general problem: in what measure the increases in EU spending on structural policies are complemented by corresponding increases in spending in the Member State? This is the principle of complementarity in the broader sense. It's necessary to determine in each case whether the problem lies in the inability of the state to perform such increases or whether it is due to other causes mentioned above. In the past the absorption difficulties were caused mainly by organizational problems in terms of national and regional parliaments. As regards the second point, the importance of regional spending in terms of balance of payments and the availability of goods and services can be determined by considering expenditure of the FESR in relation to GDP of countries and regions receiving the contributions. In recent years the ERDF has granted to Objective-1 regions contribution of $0.7 \%$ of their GDP; in the countries for which the whole country is concerned (Ireland, Greece and Portugal), this percentage varies from $1 \%$ to $1.5 \%$. Considering that the other two structural funds are intervening in favor of regional development, it can be seen as the Community contributions have reached a total of $1.2 \%$ of the Objective-1 regions GDP [9]. Complementarity remains obviously of great importance, in order to have results at regional level, so that the direct and indirect effects of resources transfer which enhance the economic potential will prove to be positive, with an increase of the regional GDP in the medium and long term, by far greater than the amount of transfer and promote - in less developed regions a growth process more quickly and consistently following the objective of economic convergence but however, it is clear that, given the gaps across regions and time required to mitigate these differences, a clear improvement of the most disadvantaged regions is bound to remain a long-term, even after the doubling of the Funds budget.

In the Community in the individuality and regional problems acquired dimensions that were previously obscured by central government and the regions was assigned a major role in the highlighting disparities and structural adjustment between member countries of the same
Community. With the Single European Act and the Maastricht Treaty [10], has begun a new think - after removing the administrative and bureaucratic centralism, especially in Italy [11] and France [12] - in terms of regional combinations, supranational, socio-economic, according to specific characteristics and cultural affinities, in the interest of a single development space-European Community. What is done in concentric circles or along linear axes has little importance, what is certain is that the denationalization of Europe pushes the aggregation of transnational interests, which were previously only regionally. The region should be seen as the main tool for the implementation of community development, unlinked from centralisms and, therefore, acting on a more rational basis [13]. It's possible to predict the progressive formation of a polarization between the nodal regions of strong central-western Community quadrant, to which will be reflected the regional economies of the first suburbs (intermediate areas), born around the main core. For other regions - those peripherals in the strict sense integration will be still far away, not so much for distance from the center, but overall for the immaturity of their production systems. Europe seems affected by significant structural and economic differences that create a very complex and full of contradictions system. In order to overcome such disparities, it is necessary to implement optimal choices of cooperation that force the Member States to binding and lasting agreements in the interest of the whole European system, chased by competition from the United States and Japan. Only by building one large European aggregate, economically and politically integrated, it's possible to start growth and development processes. This objective, however, collide with the deep regional-level differences within the Community. For these reasons, the process of European integration can't ignore the contribution of regions, arranged in hierarchies of levels of functional development. The integration will go through regionalization Community.

Whereas the presence of economic power centers is significantly differentiated within the Member Countries, it is possible that the location of production activities and wealth tend to remain - at least initially - concentrated in developed regions, to branch out slowly towards the more peripheral areas. The risk that the peripheries [14] increase its marginality towards development processes represents a real possibility and perhaps the solution of the problem lies in the EU Structural Funds. Probably it will be these funds, such as a rebalancing intervention tool, to shape the Community regions in the direction of a global growth increasing, in the name of homogeneity and uniformity.

\subsection{The Enlargement Agenda}

Approximately twenty years ago, while the Yugoslav wars were destroying the Western Balkans, the European Union established the conditions of accession to the EU for the future Member States known as "The Copenhagen criteria". Substantially, those criteria reflected the EU's fundamental 
values: democracy, state of law, respect for fundamental rights and the importance of a functioning market economy [15]. A path towards a great historic transformation was being prepared, as Central and Eastern Europe would at last become new members of the EU. In 2003, the European Council met in Thessaloniki and granted the Western Balkans a clear accession prospect [16], provided they respected the necessary conditions, among which were the Copenhagen criteria and the Stabilization and Association Process (SAP). Croatia was the first Western Balkan country meeting those requirements. After its Treaty of Accession was ratified by the European Council, Croatia was welcomed as a new Member State of the EU on 1 July 2013. The annexation of Croatia to the European Union is an example of the EU's transformational power and of the stabilizing effect of the enlargement process. The historic agreement negotiated between Serbia and Kosovo in April 2013 is a further demonstration of the strength of the European Union and of its power of healing historic wounds. It also highlights the courage of the two countries' political leaders to pursue the enlargement objective. In June, the European Council started the Serbian accession negotiations and approved the opening of the negotiations for a Stabilization and Association Agreement (SAA) between Kosovo and the EU. 2013 was very important for the other candidate countries as well. In June, Montenegro adopted global action plans as far as judicial system; fundamental rights, freedom and security were concerned, according to the new approach. In Albania, the cross support to the parties for the structural reforms, the regular execution of the parliamentary elections and further enhancements in the fight against corruption and organized crime have hastened the run towards becoming a new potential Member of the European Union.

The Former Yugoslav Republic of Macedonia exited political crisis only at the beginning of the year. Despite measures improving good neighborly relations were adopted, such shortcomings as the lack of freedom of expression and of the media still represent a major concern. In Bosnia-Herzegovina, the lack of a political efficiency in the implementation of the reforms and, specifically, the missed implementation of the Sejdic and Finci judgment (decided by the ECtHR), thwarting both the advancement of the country's accession to the EU and its economy.

Turkey achieved some advancements in the judicial reforms, and the long-awaited "democratization package" was adopted in September. Peace talks with PKK aimed to end violence and terrorism in South-East Turkey and pave the way for a solution to the Kurdish question. Nevertheless, protests following the plan to remove Istanbul's Gezi Park proved that the EU's help was the only way towards the implementation of the reforms. Iceland's new government suspended the negotiations for the accession to the EU, and stated that its membership had to be first subject to a national referendum in 2014, which eventually was not held. This type of behavior and the several inconsistencies with the European dispositions clearly demonstrated a weak propensity towards its entry into the EU.
Nowadays the accession process is stricter and more complete than it was in the past. It now reflects the evolution of the European policies and all the lessons the Union learnt from previous enlargements. The process must be performed in accordance with impartial but rigid conditions leading to progress, and the accession depends on the measures each Member State adopts to meet the requirements established by the Commission. To read correctly the past means to build the EU successfully [17].

The rule of law is at the core of the enlargement process. The new approach (decided by the Council in December 2011) claims that the candidate country must promptly tackle delicate questions such as judicial reforms, fight against organized crime and corruption so as to be allowed the accession negotiations. By maximizing those times, the potential Member State should be able to develop a solid base for the implementation of the reforms and to grant their consolidation and irreversibility. The new approach represents a key element for Montenegro which could be used by the Commission as a reference model for the other candidates. The past five years' global crisis urged all the States (particularly the Western Balkans since they all lack a functioning market economy) the importance of reviewing and strengthening their economic governance. By and large, they all share high unemployment rates, especially among youngsters. It is essential for these countries to intensify their reforms in order to restore the growth to a sustainable level, face all the challenges necessary for the EU's economic requirements, and improve their competitiveness. The European Union has often stressed the importance of the reinforcement of the democratic institutions and of those processes supporting the fundamental democratic principles shared by the EU itself. On the one hand, integration needs civil society to have a stronger influence. On the other, progresses as far as electoral, parliamentary and administrative reforms are as important. The European Union is founded on common values and principles, among which is the respect for the fundamental rights. All the Western Balkans and Turkey should undertake further reforms to guarantee the principles of freedom of expression and the safeguard of the rights of persons belonging to minorities. However, sharper measures protecting other potentially vulnerable groups (particularly for reasons concerning their sexual orientation) ought to be implemented as well.

The essential elements towards a stabilization and association process are, without a doubt, good neighborly relations and regional cooperation. The positive example of Serbia and Kosovo proved that it is possible to overcome all the difficulties resulting from the conflicts, in line with the very founding principle of the EU. Since the regional cooperation needed a further reinforcement, the European Commission completely supported the commitment of the South-East European Cooperation Process (SEECP) and that of the Regional Cooperation Council (RCC), including the SEE 2020 Strategy. Bilateral disputes among potential Member States and the effective ones are the first obstacle to 
break for a mild accession process. The second Instrument for Pre-accession Assistance (IPA II) was launched in 2014 with the aim of supporting the potential future Members of the EU from 2014 to 2020, its amount equal to $€ 11.7$ billion at current prices. IPA II also supports regional and cross-border cooperation and focuses on common interest areas. In fact, it will focus on everything that concerns the implementation of reforms in the field of law, so as to strengthen the democratic institutions and the territorial governance, and encourage the socio-economic development. IPA II is also a good opportunity to guarantee a stronger link between the enlargement strategy and assistance priorities. With its important innovations, this instrument highlights the definition of long-term policies and strategies in just a pre-defined number of primary fields, according to every country's specific needs and qualities. Clear purposes and realistic indicators are the key words. Those beneficiaries that meet the standards of public finances management will receive a further budget support, while those that perform unsatisfactorily will have to return the money. IPA programs are also rationalized into a moderate number of relevant projects [18].

All the enlargement countries act according to their European plan. Every kind of progress towards accession depends on the measures they adopt to try and meet the fixed criteria. All of that is fundamental for the EU to continue supplying subsidies to the potential new Member States, and for new significant reforms to be implemented [19]. However, it is also important that the Member States and the EU institutions conduct well-informed debates about the political, economic and social impact the enlargement policy entails. In fact, it is their duty to inform the citizens of the developments of this policy and to depict its potential benefits and its significant contributions to peace, security and prosperity.

\section{Materials and Methods}

In order to obtain a graphical and numerical reading about the economic condition of the countries that require the entry in the European Union, we have constructed a model containing some variables, able to explain countries more or less predisposed to the entrance in the European Community [20]. In this way, through the analysis of the reports for each country - considering the year 2012 - the following variables were included in the model: the Gross Domestic Product (GDP); the capital reserves (ReserveAssetValue), defined as the amount of capital available for the provision and able to cope debts or unexpected credit losses; Foreign Direct Investment (NetFDI), which can provide an indication about the possibility of the country to export capital abroad and gain control of company and actions in the attracting-investments countries, generally those with an open economy with a skilled workforce, which express a reasonable chance of growth and - finally - the unemployment rate. The first three indicators are expressed in million euros while the final is in percentage value on the population.

Table 1. Data framework - Variables and Countries

\begin{tabular}{|c|c|c|c|c|}
\hline & GDP & ReserveAssetValue & NetFDI & UnemplRate \\
\hline Turkey & 614459 & 90332 & 6573 & 8.2 \\
\hline Macedonia & 7490 & 2193 & 111 & 31.0 \\
\hline Serbia & 29932 & 10914 & 232 & 23.9 \\
\hline Montenegro & 3346 & 348 & 462 & 19.7 \\
\hline Kosovo & 4776 & 575 & -16 & 35.1 \\
\hline Bosnia\&H. & 13117 & 3328 & 273 & 28.6 \\
\hline Albania & 9370 & 1972 & 745 & 13.9 \\
\hline
\end{tabular}

After an initial screening of the variables considered not significant for the model, appropriately eliminated through the procedure backwards elimination - excluding the repressors who had a regression coefficient greater than the significance level established - it was estimated the linear model shows the regression results. At this point, all the variables taken into consideration are significant.

Table 2. Linear model

\begin{tabular}{|c|c|c|c|c|}
\hline & Estimate & Std. Error & $\mathrm{t}$ value & $\operatorname{Pr}(>|\mathrm{t}|)$ \\
\hline (Intercept) & $3.363 \mathrm{e}+01$ & $9.580 \mathrm{e}-01$ & 35.104 & $5.08 \mathrm{e}-05 * * *$ \\
\hline $\begin{array}{c}\text { Reserve } \\
\text { Asset } \\
\text { Value }\end{array}$ & $-1.622 \mathrm{e}-03$ & $2.814 \mathrm{e}-04$ & -5.764 & $0.01038 *$ \\
\hline NetFDI & $-2.932 \mathrm{e}-02$ & $2.428 \mathrm{e}-03$ & -12.076 & $0.00122 * *$ \\
\hline GDP & $5.108 \mathrm{e}-04$ & $5.685 \mathrm{e}-05$ & 8.984 & $0.00291 * *$ \\
\hline
\end{tabular}

Notes: 1 ) Signif. codes: 0 ‘***’ 0.001 '**’ 0.01 ‘*’ 0.05 '.’ 0.1 ' ’ 1 ;

2) Residual standard error: 1.421 on 3 degrees of freedom;

3) Multiple R-squared: 0.9891, Adjusted R-squared: 0.9782;

4) F-statistic: 90.65 on 3 and 3 DF; 5) p-value: 0.001928

At this point we observe a graphical summary of the diagnostic regression through four charts that indicate respectively: the residuals against the theoretical values, which put out anomalies when the distribution of the points does not happen randomly, which doesn't happen in our case confirmed the effectiveness of the model; the plot of standardized residuals, which graphically shows the normality of erratic component of the linear model, which confirms the veracity of the assumptions of the model, since the points lie near the line Q-Q; the third graph is useful for diagnosis of any outlier values and structures of residual dependency identified by the model and the last graph concerning the Cook's distances expresses the relative influence of each observation on the estimated model parameters. 


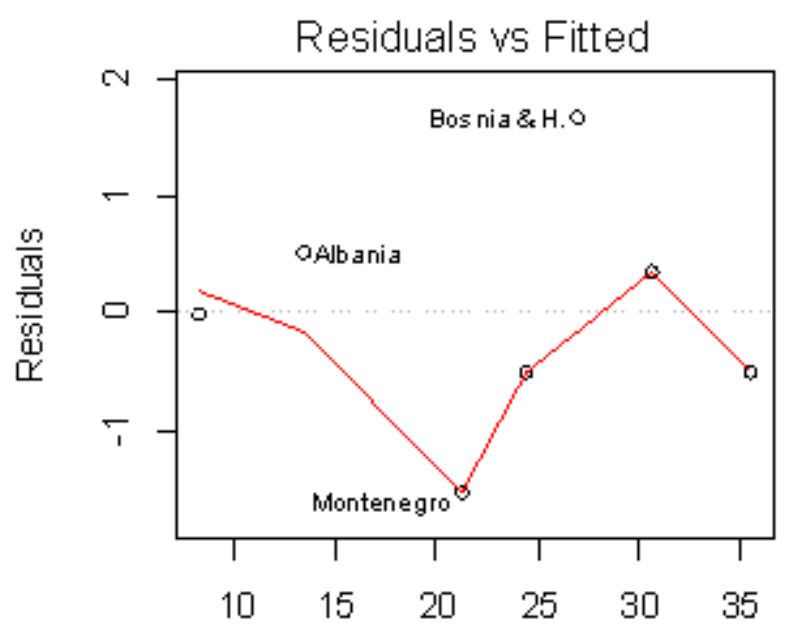

Fitted values

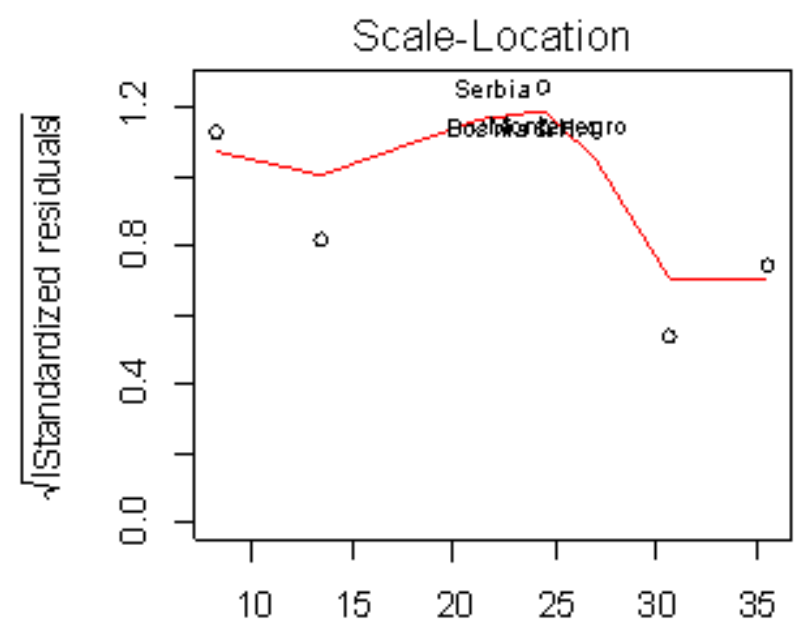

Fitted values

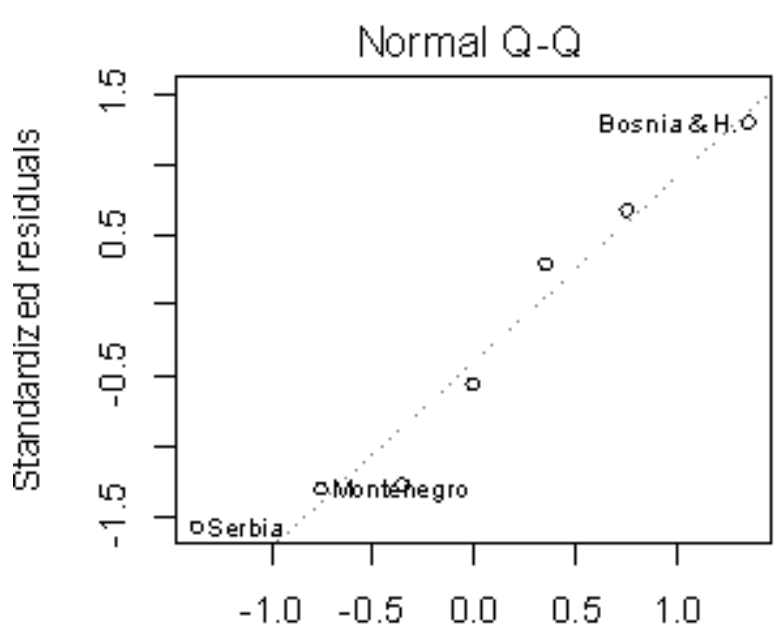

Theoretical Quantiles

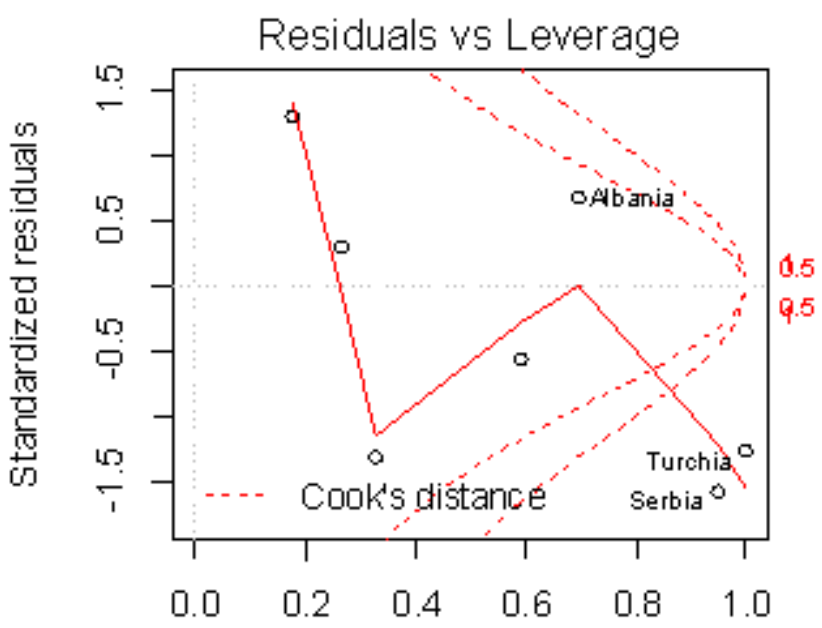

\section{Leverage}

Figure 1. Diagnostic Summary Plots - Part 1, 2, 3, 4. Source: personal graphic processing by Dr. Dante Di Matteo

Later, we have observed the regression coefficients correlation between all variables of the model: the intercept (unemployment rate) is positively correlated with the repressors $G D P$, unlike the other two, which have negative values. Similarly, there is positive correlation between variables NetFDI and ReserveAssetValue.

Table 3. Variables correlation

\begin{tabular}{|c|c|c|c|c|}
\hline & (Intercept) & Reserve Asset Value & NetFDI & GDP \\
\hline (Intercept) & 1.0000000 & -0.6661499 & -0.6741768 & 0.7649388 \\
\hline Reserve Asset Value & -0.6661499 & 1.0000000 & 0.4520135 & -0.9173893 \\
\hline NetFDI & -0.6741768 & 0.4520135 & 1.0000000 & -0.7674351 \\
\hline GDP & 0.7649388 & -0.9173893 & -0.7674351 & 1.0000000 \\
\hline
\end{tabular}

It is also possible to trace the plot of all variables contained in the data frame with the response variable. From what appears in the following graph, it is clear how the linearity doesn't seem to be good for variables NetFDI and ReserveAssetValue, where the points do not line up randomly within the plot. 

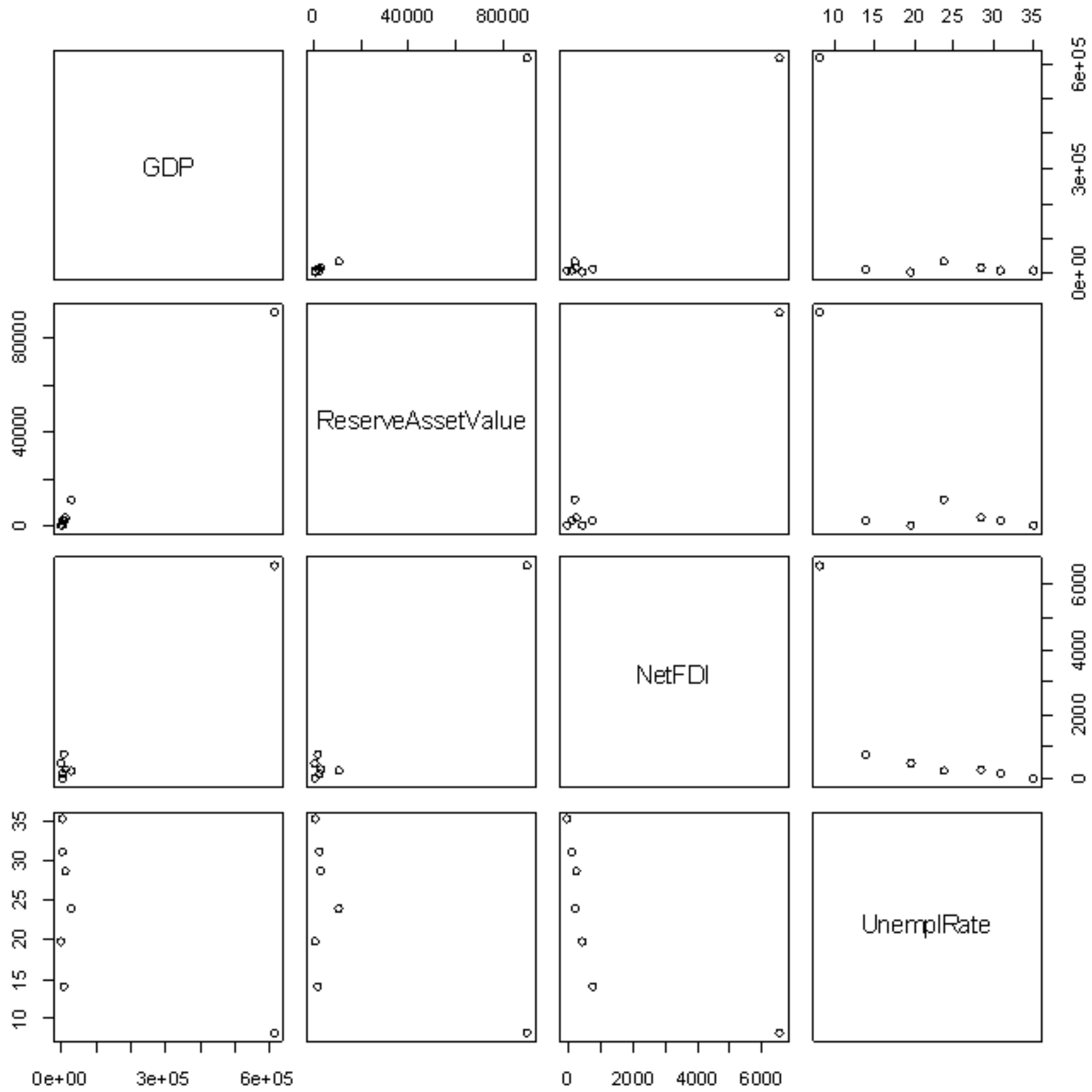

Figure 2. Variables correlation plot. Source: personal graphic processing by Dr. Dante Di Matteo

After estimating the regression model it is appropriate ensure that the assumptions underlying the model are valid across different specification tests, among which the t-student, the Shapiro-Wilk (normality test), the Breusch-Pegan (homoscedastic of residuals) and the Durbin-Watson (absence of serial correlation). In all cases, the specification tests give a positive result, so the assumptions underlying the OLS regression model are to be considered valid. It is now possible to trace the plot about the leverage points (hat values), with low residuals. 


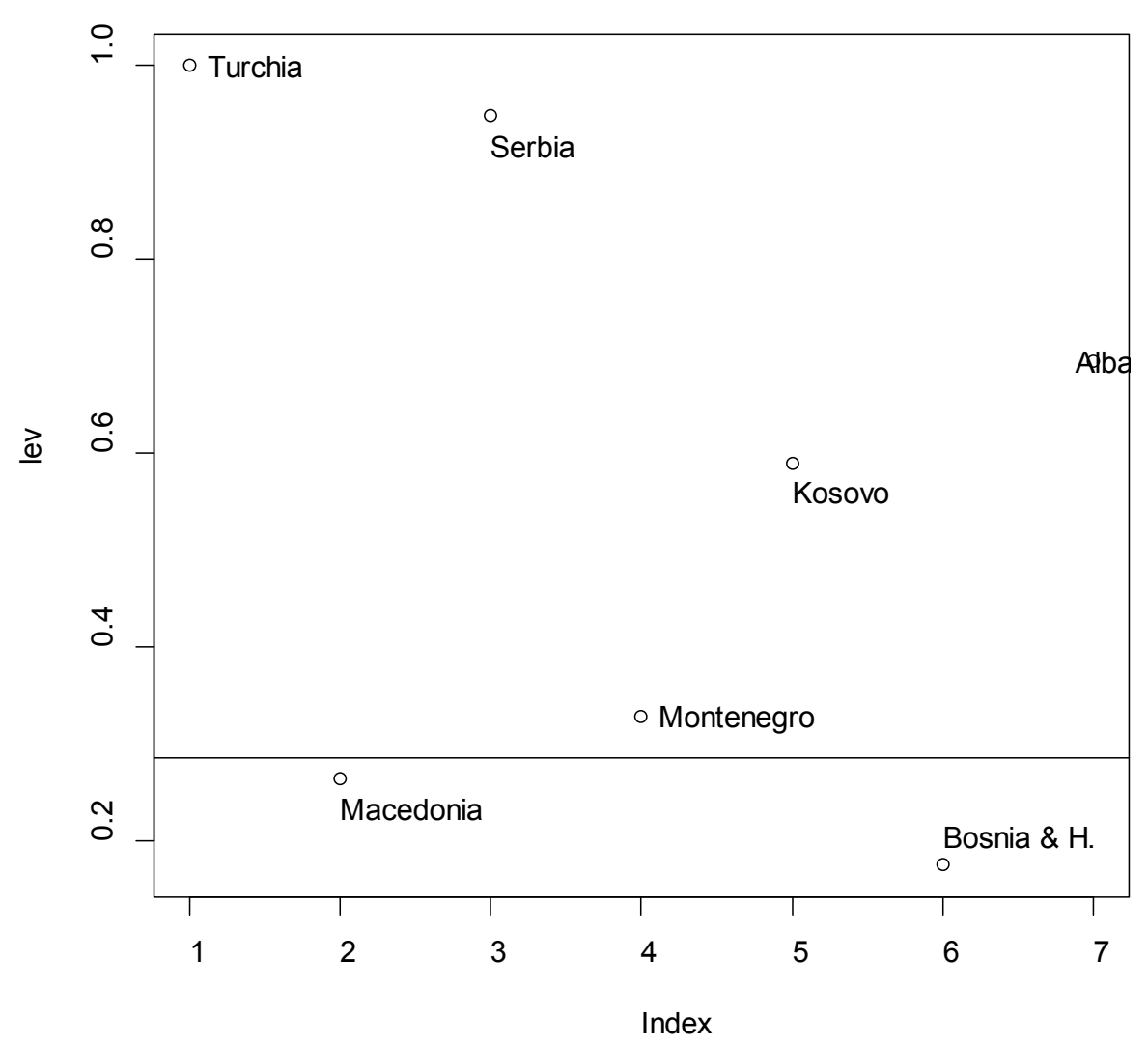

Figure 3. Hat values plot. Source: personal graphic processing by Dr. Dante Di Matteo

Finally, through the graph relative to the influence point, it's possible to identify those leverage points such that their removal can produce a significant change in the estimate of the parameters.

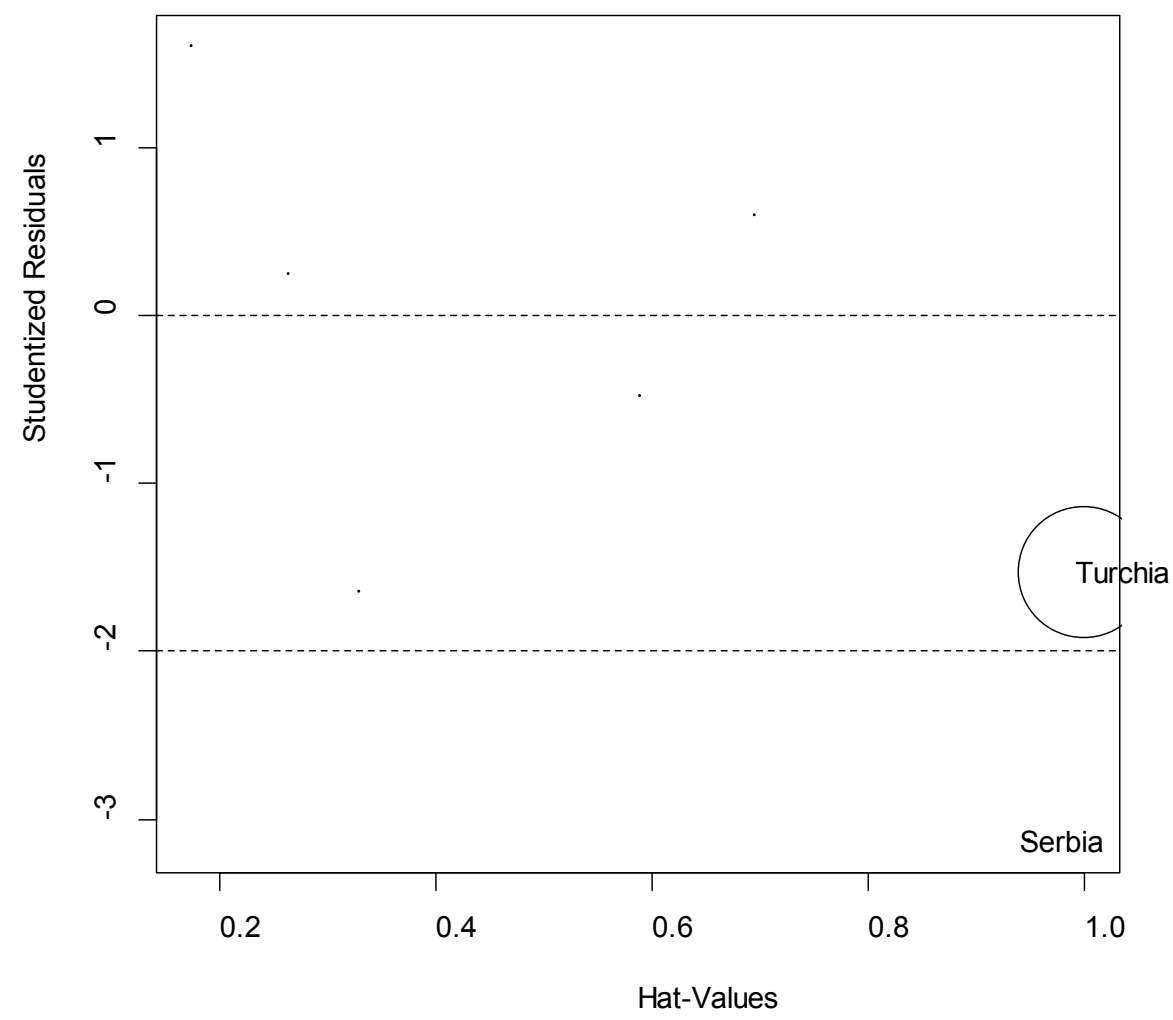

Figure 4. Influence plot. Source: personal graphic processing by Dr. Dante Di Matteo 


\section{Results and Discussion}

This section may now follow by drawing a possible conclusion for every mentioned country. As far as Montenegro is concerned [21], its launch of the accession negotiations in 2012 marked the new opening to a path towards the entry into the EU. The accession process should be inclusive and witness a strong participation of the civil society. Montenegro adopted detailed action plans entailing a global reform project aimed at reinforcing the role of the law. The implementation of these plans and the advancements towards the required parameters will determine the overall cadence of the accession negotiations. In this regard, implementing constitutional modifications will strengthen the independence of the judicial power, so further advancements in the fight against organized crime and corruption are to be expected. The public administration reform is essential for this country to be allowed to apply the acquis and boost the transparency and the competence of its civil service. In the past few years, some unpleasant events such as the alleged use of public funds for political parties' purposes evidenced the urge to strengthen the citizens' trust in the public institutions. There is a lot to be done in terms of freedom of expression. Furthermore, all the cases of violence and threats against journalists should be examined carefully and undergo the due sanctions. As for its economy, improvements in the fabric of production and fighting against the high unemployment rate are the two most urgent questions. Montenegro showed some advancement towards a functioning market economy. In fact, it should be able to face the competitive pressures of the EU in the medium term, provided it continues to face its current weaknesses with appropriate macroeconomic policies and structural reforms. Despite entering recession in 2012 , the country exited it in 2013. Resilience in tourism, in foreign direct investments, and increases in electricity exportations contributed to support the economic recovery and compensate the weak domestic demand. Montenegro should strengthen its competitiveness, enhance productivity and attract further foreign direct investments in the fields of tourism and of real estate industry in order to face the external threats. The weak state of law and the prevailing corruption obstruct the creation of a strong economy. The high unemployment rate suggests the gap between the demand and the supply of work competence should be filled, consequently allowing defining more independent business wages. Public job centers should be reinforced as well, so as to guarantee a more inclusive and efficient labour market. Budgetary consolidation and collection of fiscal arrears should also be pursued.

The Council's decision to open the accession negotiations to Serbia in June 2013 represents a new significant step for the EU-Serbia question [22]. It is the acknowledgement of all the progresses performed by this country in the key reforms, and of the hard work invested in the normalization of its relations with Kosovo. When the Stabilization and Association Agreement was implemented, Serbia actively worked for tangible results. The "First Agreement of Principles Governing the Normalisation of Relations with
Kosovo" was presented in April and implemented in May. In addition to these first good results, Serbia must be continued to respect all the aspects of the Agreement, including the parts relating to energy and telecommunications. The European Commission started the acquis analytical examination in September 2013. The other critical points concern law, implementation of the judicial reform, fight against corruption and organized crime, reforms of the public administration, independence of the principal institutions, freedom of the media, fight against discrimination, and safeguard of the rights of persons belonging to minorities. Serbia should also enhance its fabric of production and boost the development of a competitive private sector. One of its major priorities is, without a doubt, to fight its high unemployment rate. That is why Serbia ought to strengthen its relations with the adjacent countries, so as to enforce regional cooperation. As for economy, 2012 was a recession year for Serbia, its economy having contracted to $1,7 \%$. Nevertheless, a fertile increase in exportations contrasted the weak domestic demand, provoking a mild recovery this country had never experienced before the first half of 2013. Both the unemployment rate and the budget deficit are still very high, since the rigid labour market and the difficult creation of a sustainable occupation persist massively. The adoption of a credible mid-term financial adjustment is still latent as the economic presence of the State is still cumbersome and the state firms have been collecting great losses.

As far as Macedonia is concerned [23], its political crisis following the parliamentary incidents in December 2012 showed how deep rifts in the political parties were. Those rifts hindered the economic and social balance of this Republic and proved that a constructive policy is needed for the sake of the whole country. The EU agenda is the strategic priority. The dialogue with the European Commission enhanced progress in the majority of the primary sectors, among which stand the elimination of judicial arrears and advancements in the fight against corruption. Macedonia has already reached a good level of accordance by the Commission, having proved its capacity of respecting all the obligations deriving from the accession. The independence of the judicial power and the results in the fight against corruption and organised crime deserve a special mention, though freedom of expression and the role of the media need more attention. The revision of the Ohrid Framework Agreement must be completed and implemented in all of its recommendations, given the high value delivered to interethnic relations. OSCE/ODIHR stressed the obfuscation of the distinction State/Parties in the electoral area. Other priorities are: fighting the high unemployment rate and managing the public finances. The European Commission deems the adopted political criteria sufficient, and invokes a prompt opening to the accession negotiation. Annexation would boost, in fact, good-neighbourly relations and a solution to the question of the name, which the Commission reckons of essential importance. Because such advices were not taken into consideration in the past two decades, the credibility of the Macedonian enlargement process could be 
questioned, since annexation is based on clear conditionality and on the principle of one's own merits. Macedonia's lack of a credible European plan threatens the sustainability of its reforms and as a consequence, its integration into the EU. The Commission in fact exhorted the country to present its proposal of a negotiating framework which entails: the solution to the question of the name first and the EU acquis analysis, the review of the judicial area and fundamental rights as far as justice, freedom and security are concerned, then. As for economy, it stagnated in 2012 but mildly recovered in the first half of 2013. Despite the foreign variable background, Macedonia tried to save its macroeconomic stability. Unemployment is still very high above all among the youngsters, and the increase in deficit and in public debt contributed to make the Republic even more vulnerable. Fiscal policy should be in line with the priorities relating to the country's structural reforms and with an increase in the public spending. The introduction of a mid-term budgetary framework and of a strategic plan might boost its fiscal discipline. Further efforts towards an efficient managing of the public finances are still needed. Macedonia could guarantee a transparent use of its public and European funds only through these proofs.

In October 2012, the European Commission recommended the Council to grant Albania the status of candidate Member State [24], provided that the key reforms in public and judicial administration were completed and its parliamentary regulations reviewed. For this reason, the Council exhorted the Commission to present Albania's achieved advancements and its efforts in the fight against corruption and organized crime two months later. The country has then adopted the remaining measures in relation to justice, public administration, and parliamentary reform with a cross approval. The last parliamentary elections were judged by an international electoral observation commission led by OSCE/ODIHR, and deemed satisfactory and compliant with the fundamental principles of freedom. An active participation of the citizens throughout the whole campaign was also registered. With regard to the fight against corruption and organized crime, Albania moved its first steps towards advancements in the efficiency of the investigations and in the hardening of the penal actions, by strengthening cooperation among the appointed institutions. Despite this promising start, convictions of corruption and money laundering have increased in the past few years. Investigations on human and drug trafficking have grown as well, in spite of the fact that the EU's recent directives on political parties funds and corruption had been tackled satisfactorily. Given the achievement of the necessary results, the Commission asked the European Council to grant Albania the status of candidate country provided the country persists in its fight against corruption and organized crime. With reference to national economy, Albania registered good advancements thanks to a functioning market economy. Though GDP increases slowly, it is constant thanks to the foreign demand and to low inflation rates. These features have in fact contributed to facilitate the monetary policy and the economic growth in general, although real effects on the economy still need to be confirmed. Budget deficit is still high, just as the public debt is, in violation of the rule that public debt cannot exceed $60 \%$ of GDP. Mild enhancements may be found in the labour market (despite unemployment remains a major problem) and in the current deficit. By and large, it is possible to maintain that Albanian economy is vulnerable both because of its internal structural weaknesses, and because of the global economic instability. The government should integrate monetary and fiscal policies through effective stability, that is to say, through structural reforms that can guarantee a long-term sustainable economic growth. Among the other priorities, Albania must concentrate on its high budget deficit, high public debt rates and the distortion of the latter. Albania must also enhance fiscal predictability by reducing the overestimation of the recurring incomes through a more efficient tax collection system. The entrepreneurial context should also be improved so as to allow economy to be diversified and its potential growth to be expanded in the long term. A more rigid fight against corruption, creation of new infrastructures, and promotion of the human capital are the country's further missions. The opening to the accession negotiations also implies that Albania must: implement the public administration reform in order to enhance professionalism and depoliticize the ruling class; adopt further measures to strengthen the independence, efficiency, and responsibility of the judicial institutions; boost the fight against corruption and organized crime through the creation of a valid register for proactive investigations, penal actions and sentences; actualize efficient measures for the human rights' strengthening and safeguard such as the implementation of anti-discriminatory policies. To conclude, Albania will also have to prove that establishing a productive and sustainable dialogue between the government and the opposition about the implementation of the Community acquis is possible. At the same time, its entry into the EU means that making strong and constructive efforts in the regional cooperation is possible as well.

Bosnia and Herzegovina's process towards the European integration is in a stalemate [25]. Sejdić and Finci judgment of the ECtHR has not been implemented yet just as any functioning project of coordination for the European questions has not been planned either. Instruments for Pre-accession Assistance (IPA) are not likely to produce the expected results without the necessary approvals, which, together with the above-mentioned facts do not allow the country to be given the general amount of the European pre-accession funds. That is why the European Commission decided to grant further possible concessions of IPA II funds, which will be lost in case of missed tangible advancements. These advancements will depend mostly on the political leaders' ability in cooperating for a compromise towards annexation. This would certainly restore the citizens' trust in the politicians' skills in leading the country towards the European integration: the Stabilization and Association Agreement would come into force, and consequently, the 
candidacy for joining the EU would then gain credibility. As for the structured dialogue on justice, the EU directives are being implemented, though the overall judicial reform has not been achieved completely. The dialogue highlights the potentialities of the enlargement program and the benefits deriving from the country's effective commitment. Some of the advancements relate to the efforts put to limit the war crimes backlog.

\begin{tabular}{|c|c|c|c|}
\hline \multirow{4}{*}{$\begin{array}{l}\text { LEGEND } \\
\text { - turkey } \\
\text { - kosovo } \\
\text { montenegro } \\
\text { - olbonio } \\
\text { - bosnlo\&herz } \\
\text { - mocedonio } \\
\text { - serbio } \\
\end{array}$} & \multirow{2}{*}{$\begin{array}{c}\text { Acquis } \\
\text { application \& } \\
\text { alignment with } \\
\text { UE requirements }\end{array}$} & $\begin{array}{l}\text { Structural reforms } \\
\text { of the Public } \\
\text { Administrations } \\
\text { and the } \\
\text { Judicial Systems }\end{array}$ & $\begin{array}{l}\text { Fight against } \\
\text { corruption and } \\
\text { organized crime }\end{array}$ \\
\hline & & $\bullet \bullet \quad \bullet$ & $\bullet \bullet \bullet$ \\
\hline & 0 & $\bullet$ & MEDIUM \\
\hline & $\bullet$ & $\bullet$ & LOW \\
\hline $\begin{array}{c}\text { Transparency and } \\
\text { Professionalism of } \\
\text { Public } \\
\text { Administrations }\end{array}$ & $\begin{array}{l}\text { Communication } \\
\text { and expression } \\
\text { freedom of } \\
\text { mass media }\end{array}$ & $\begin{array}{l}\text { Entrepreneurial } \\
\text { improving } \\
\text { and Infrastructure } \\
\text { development }\end{array}$ & $\begin{array}{c}\text { Fiscal } \\
\text { consolidation and } \\
\text { Public Finance } \\
\text { Management } \\
\text { improving }\end{array}$ \\
\hline HIGH & $\bullet$ & $\circ \bullet$ & HIGH \\
\hline MEDIUM $\bullet$ & $\because$ & $\bullet \bullet$ & $\because \bullet$ MEDIUM \\
\hline LoW & 60 & ق & LOW \\
\hline $\begin{array}{l}\text { Reduction of } \\
\text { Unemployment } \\
\text { and rigidity in the } \\
\text { Labor Market }\end{array}$ & $\begin{array}{c}\text { Anti discrimination } \\
\text { minority protection } \\
\text { strengthening of } \\
\text { Human Rights }\end{array}$ & $\begin{array}{l}\text { Increase exports } \\
\text { and growth in } \\
\text { Public Spending }\end{array}$ & $\begin{array}{l}\text { Decentralization } \\
\text { and Privatization } \\
\text { of State } \\
\text { Enterprises }\end{array}$ \\
\hline$\bullet \bullet \bullet \bullet \bullet$ & $\bullet \bullet \bullet \bullet \bullet$ & $\circ \circ$ & HIGH \\
\hline MEDIUM & $\cdots$ & 6 & MEDIUM \\
\hline LoW" & $\because$ & $\because 6$ & $60^{\circ}$ \\
\hline $\begin{array}{c}\text { Reducing } \\
\text { Public Debt } \\
\text { and the } \\
\text { Balance Deficit }\end{array}$ & $\begin{array}{c}\text { Improvement } \\
\text { in Working } \\
\text { Contractual } \\
\text { Terms }\end{array}$ & $\begin{array}{c}\text { Regional } \\
\text { Cooperation }\end{array}$ & \\
\hline$\bullet \quad \bullet$ & ㅇ․ & $0 \quad 000$ & HIGH \\
\hline 00 & $\bullet$ & … & MEDIUM \\
\hline Low & $\bullet \bullet \bullet$ & $\bullet$ & Low \\
\hline
\end{tabular}

Figure 5. Priority Chart - Balkan Countries. Source: personal graphic processing by Dr. Dante Di Matteo 
Furthermore, thanks to the support of the EU and of other international organizations the long-awaited census has been made possible. Despite economy contracted of $1,1 \%$ in 2012, the indicators of the first semester of 2013 showed some signs of recovery while the unemployment rate is still very high. The public financial management system slightly improved, in spite of the presence of some serious gaps. The essential elements of fiscal and economic policy are still weak and obstruct the implementation of national reforms. The vast and inefficient public sector (where several state competences overlap) weakens the financial sustainability. An inefficient juridical and judicial system instead weakens the implementation of reforms and provides a fertile source of corruption while limiting potential investments. The inefficient public spending represents a major concern for the Bosnian development. Its financial activities report should be improved in order to enhance the quality of the examinations and boost policies planning. Other intervention measures that need attention relate to the excessive tax on labour, the unjust decentralization of social transfers, encouraging the demand for labour, and reforming the pensions. Since public firms are preponderant, authorities should invest instead in privatization, enhance the application of labour contracts, and set a unique economic framework. The country needs to face big challenges such as: amending the state of law and the judicial reform, fighting against corruption and organized crime, revising public administration reforms, enhancing the freedom of expression, defining actions against threats suffered by journalists, and ending discrimination (with a special focus on the Romani question). The region's refusal to adapt the Stabilization and Association Agreement after the EU accession of Croatia is deemed inacceptable by the European Commission, given the commercial relations these two countries have always maintained. $\mathrm{BiH}$ has been exhorted to reconsider its position so as to allow a new adaptation of the traditional commercial relations.

2013 was a pivotal year for Kosovo in terms of its path towards annexation [26]. The Council's authorization for the openings of the SAA represented the beginning of a new significant phase in the European question. In fact, the Union acknowledged the Kosovan advancements in the key reforms and the efforts the Republic put for the achievement of a concrete and enduring normalization of its relations with Serbia. The accession negotiations will be opened this month. In April 2014, the dialogue between Kosovo and the EU produced the "First Agreement of principles governing the normalization of relations with Serbia". It was completed in May and has already contributed to make important changes in the territory. Kosovo's commitment must continue in this direction. It must boost the normalization of its relations with Serbia and implement all the objectives traced in the dialogue. The first result of this commitment concerns the agreements on energy and telecommunications. Thanks to these results, the Commission dispensed extra IPA funds to boost the "First Agreement" implementation between the communities. The fight against corruption and organized crime, public and judiciary administration reforms, minority rights, and commercial questions should be treated as further priorities. Moreover, Kosovo must promptly tackle the questions of unemployment and of the structural shortages in the labour market. The complicated economic situation of the region and of the EU started to affect Kosovo's economy, though less than in other countries. In fact, its GDP increase of 2,5\% in 2012. Though unemployment rate is still high, a judicially binding fiscal normative was introduced, and Kosovo continued to invest significantly in its infrastructures. The country must boost competitiveness among the firms by supporting the private sector and thus reduce unemployment.

To conclude, a particular comment on Turkey needs to be expressed [27]. It is one of the most suitable candidates for the Eurozone. Its great and dynamic economy makes the country a very important partner for the EU. Its strategic geographic position (as far as the energetic security is concerned) assigns Turkey a major role in the regional Community politics. The "Positive Agenda" launched by Commission in 2012 supports the accession negotiations of Turkey but it does not substitute them. Turkey must perform a credible and active accession process, where the EU stands as the anchor for its political and economic reforms. Intensified relations between Turkey and the Member States of the EU should help the cooperation process. In the past few years, several important advancements in the reforms have been performed. The fourth judicial reform package strengthens the safeguard of the fundamental rights such as the freedom of expression and the fight against impunity of torture and abuses. The government started a historical peace process in order to stop terrorism and violence in Southeast Turkey and start a solution to the Kurdish question. Some of the further measures of the package include reforms on the use of other languages in addition to Turkish, minority rights, the number of the parliamentary representation, and political parties funding. Also, the implementation of cooperation with stakeholders according to the European criteria is very important. The Conciliation Committee (instituted in order to draft a new Constitution) has already agreed upon the adoption of an organic law on strangers and on the international protection, so as to grant the appropriate protection to the demanders of political asylum. Turkey in fact had a major role assisting the copious number of Syrians fleeing their country. Another positive element in favour of annexation is the ratification of the Trans Anatolian Pipeline Agreement. This pact formalizes the commercial relations with the Trans Adriatic Pipeline, that is to say the project relating to the transportation of natural gas from the Caspian Sea to the EU through Turkey. Nevertheless, there are other points that should undergo revision, such as the excessive use of force by police and the general lack of dialogue during the manifestations of May and June 2013. The Turkish judicial system also needs to strengthen the freedom of expression and of the press and the freedom of association. As for Turkey's economic background, while economy increase of 9\% in 2010 and 2011, the GDP slowed down and stopped to $2,2 \%$ in 2012 . This process was counterbalanced by the growth of the domestic demand to the detriment of the external trade, the temporary constriction of the current 
account deficit, and by a general fall in inflation. The GDP increased again up to $3,7 \%$ in the first half of 2013, while the current account deficit widened and the consumer price index accelerated again. In relation to the European standards, the public debt with reference to the GDP continued to decrease up to $40 \%$. Financial markets are now under pressure because of internal and external factors and the central bank reacted by stabilizing the exchange rate including capital outflows. These last economic performances show the Turkish high economic potential on the one hand, and its permanent economic imbalances on the other. Its dependence on the capital inflows financing the structural deficit of the current accounts exposes Turkey to the global risk, thus entailing wide fluctuations of the exchange rate and economic stagnation. This exposition may be resolved through measures of financial policy enhancing national savings. In fact, the adoption of a fiscal rule would boost the budget transparency and strengthen Turkey's economic credibility. Turkey may then accelerate its accession negotiations, provided all of its obligations towards the European Union are always accomplished. The Readmission Agreement ratification and the simultaneous start of the dialogue on the visa liberalization would lead to concrete benefits both for Turkey and the EU. Energetic cooperation and advancements in the accession negotiations would facilitate the interconnection of the parties' energetic markets. In light of what has been stated about the social, political and economic conditions of the seven analyzed Balkans, Figure 7 summarizes graphically the priorities each part needs to assume. Fourteen observation criteria have been presented, along with a three-levels priorities scale which depicts the index of priority for the execution of the intervention according to the observed variable. The legend characterized these seven countries in seven different colours so as to allow an easy intuition of the prerogatives that still lack solutions and of those that have been (partially or entirely) resolved.

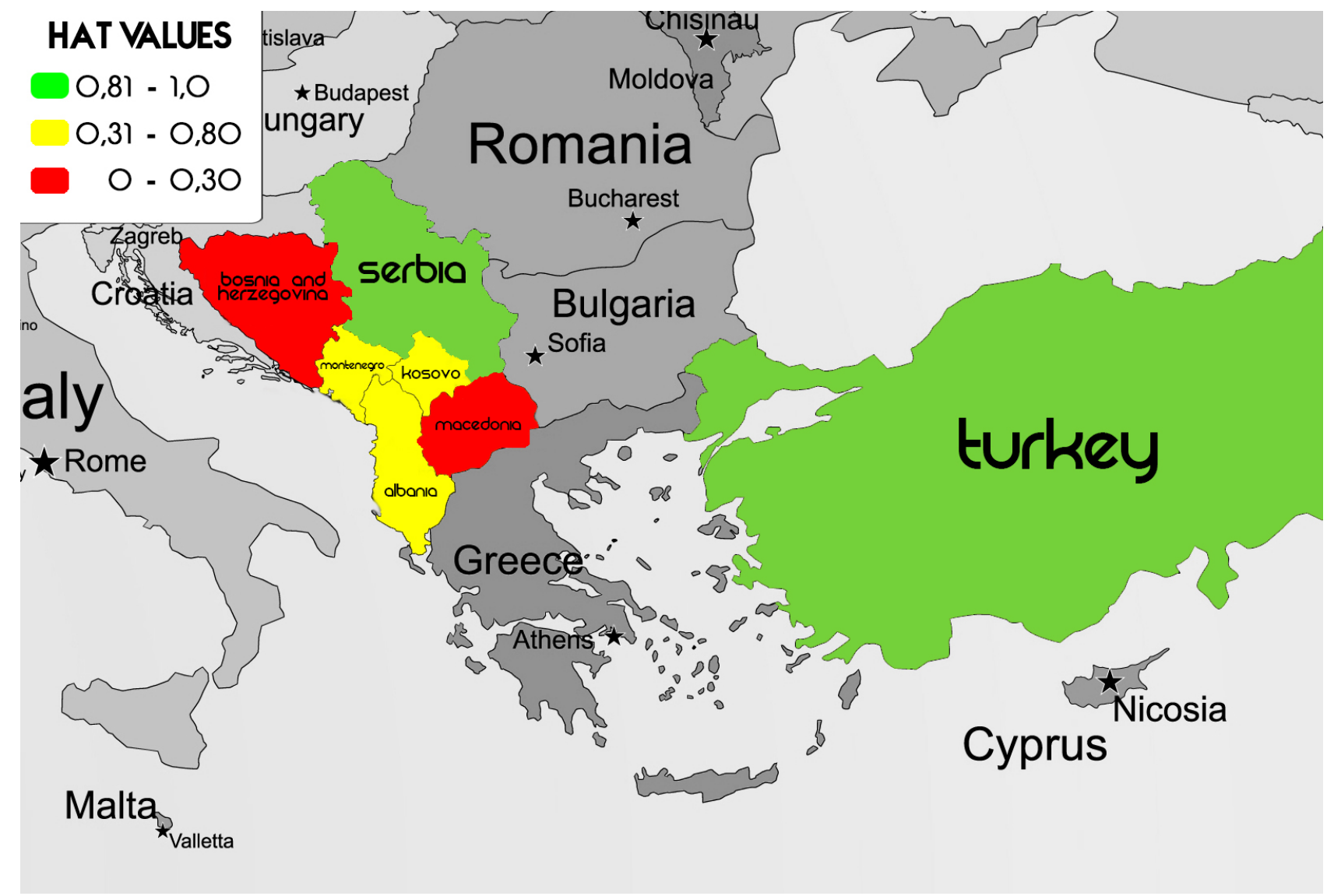

Figure 6. Hat Values Map - Balkan Countries. Source: personal graphic processing by Dr. Dante Di Matteo 


\section{Conclusions}

In view of the analysis described above, it is possible to delineate rather precise scenarios of the EU candidates' economic and social backgrounds. As the variables used for Eastern Europe's socio-economic trend demonstrate, Turkey and Serbia are the two most suitable applicants for the EU.

The unemployment parameter has been related to the Gross Domestic Product, the capital reserves and the foreign direct investments flows, so as to establish how the level of variation and incidence of the unemployment parameter alters when the other indicators change. As the variables correlations chart shows, a positive correlation between the regressor (unemployment) and the explanatory variable (GDP) may be traced. This link proves that as unemployment raises, GDP decreases. On the contrary, the chart demonstrates that the correlation of capital reserves and foreign direct investments to the regressor is negative. A high unemployment rate corresponds to a low foreign direct investments level and to low capital reserves quantities. Figure 6 shows rather clearly both the positive and the negative values of the applicant countries. According to this illustration (and consequently to the values taken into consideration), Turkey certainly emerges as the most appropriate candidate for the accession. The autocorrelation effect then, displays the remaining countries in relation to the highest values. This figure thus demonstrates that the second most appropriate candidate to become a EU Member is Serbia. While Albania, Kosovo and Montenegro stand between the highest and the lowest hat values, Macedonia's and Bosnia and Herzegovina's figures reveal these countries are not ready to join the European Union yet.

Figure 6 shows that the estimation of the parameters may dramatically change when all the observations about Turkey (and Serbia to a lesser extent) are eliminated from the model. This confirms what had been previously shown: the two countries' strong influence among all of the applicants for accession. In other words, while Turkey and Serbia may effectively be deemed potential Member States (according to the considered values), the others' values are too low so as to aim for the European membership. The entry into the European Community would in fact thwart their economy rather than enhance some of the essential standards the EU countries already have.

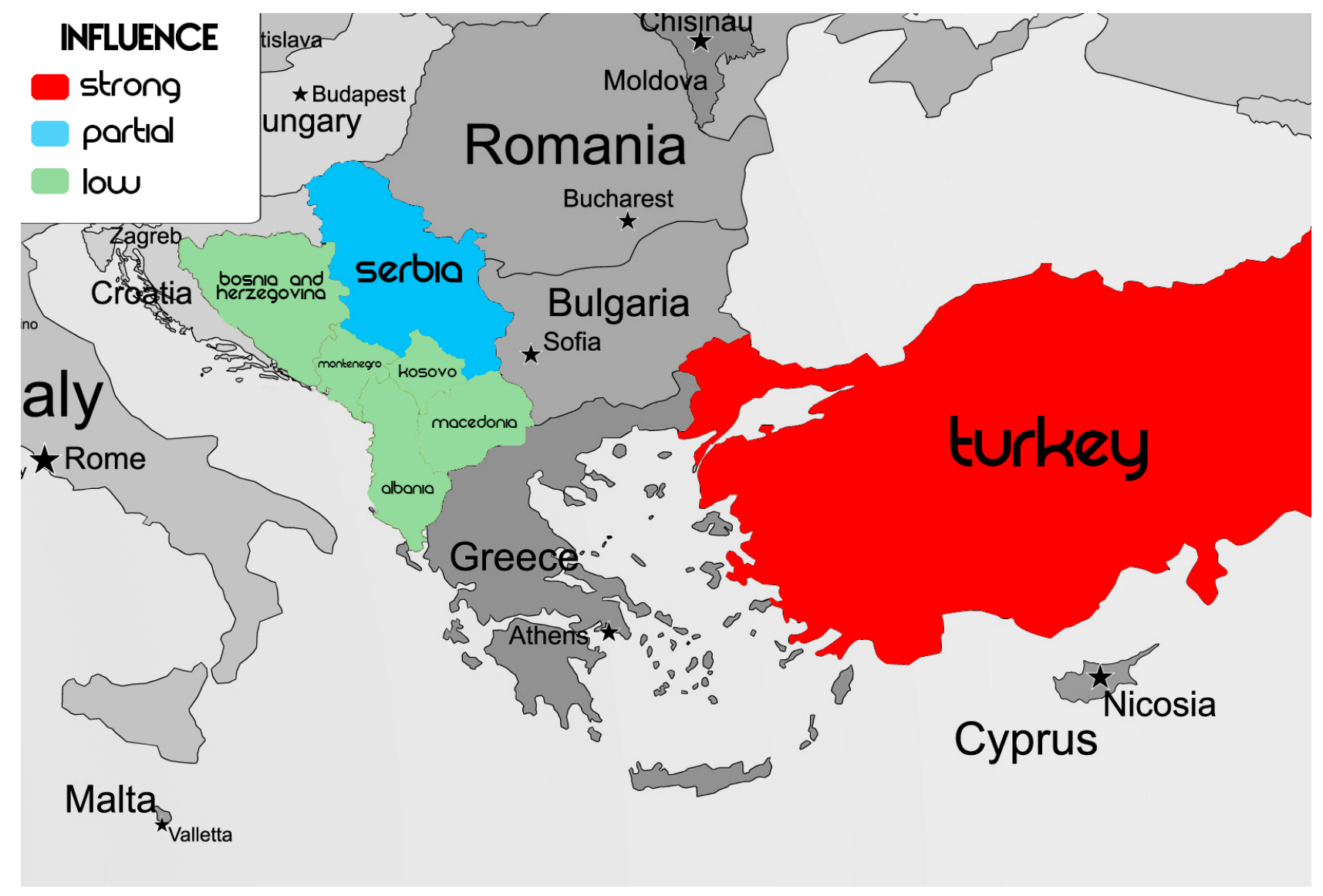

Figure 7. Influence Map - Balkan Countries. Source: personal graphic processing by Dr. Dante Di Matteo 


\section{Acknowledgements}

Although this work is the result of common reflection, Professor Cavuta is the author of paragraphs 1 and 2, while Dr. Di Matteo is the author of paragraphs 3 and 4 . Conclusions are in common.

\section{REFERENCES}

[1] R. Bernardi. Europa 1992: considerazioni sulle dinamiche economiche e territoriali, Rivista geografica italiana, XCVI, Soc. Studi Geogr., n 1, Firenze, 1989.

[2] Commissione delle Comunità Europee. Squilibri regionali e performance delle economie nazionali, Bruxelles, 1985.

[3] I. Cipolletta. Le imprese nel sistema statistico europeo, contributo al Convegno di studi «La statistica italiana per l'Europa 1993», CNR, Roma, 1990.

[4] Commission of European Communities. Financing of small and medium-sized enterprises in assisted regions, Bruxelles, 1990.

[5] Commissione delle Comunità Europee. Terza relazione annuale sull'attuazione della riforma dei fondi strutturali, Bruxelles, 1991.

[6] Commission of European Communities, Programme of research and action on the development of the labour market, Bruxelles, 1993.

[7] Commissione delle Comunità Europee. Fondo europeo di sviluppo regionale, $14^{\circ}$ relazione annuale, Bruxelles, 1990.

[8] Commissione delle Comunità Europee. I fondi strutturali 1994-1999, prospettive e modalità di gestione delle iniziative comunitarie, Bruxelles, 1993.

[9] W. Molle. Regional disparity and economic development in the European Community, The University Press, Cambridge, 1987.

[10] F. Pocar, C. Secchi. Il trattato di Maastricht sull'Unione Europea, Giuffrè, Milano, 1993.

[11] T. D'Aponte. L'Italia nel contesto internazionale, Linee di ricerca dell'Ass. dei Geografici Ital., Pàtron, Bologna, 91-110, 1993.

[12] Commission des Communantes Europeennes. Economie européenne, $\mathrm{n}^{\circ}$ 54, Bruxelles, 1993.

[13] Commission of European Communities. Urban problems and regional policy in the European Community, Bruxelles, 1988.

[14] D. Keeble, J. Offord, S. Walter. Peripheral regions in a Community of twelve Member States, Cambridge University, London, 1986.

[15] G. Mele. Allargamento a est dell'Unione Europea: il quadro di riferimento per le politiche comunitarie di sviluppo regionale e coesione, Politiche Territoriali Confindustria, CSC Working Paper n²9, Roma, 49-57, 2001.

[16] European Commission, Directorate-General for Economic and Financial affairs. Enlargement, two years after: an economic evaluation, Bureau of European Policy Advisers, European Communities, Bruxelles, 68-75, 2006.

[17] European Commission. Communication from the Commission to the European Parliament and the Council, Enlargement Strategy and Main Challenges 2013-2014, Bruxelles, 25-44, 2013.

[18] Eurostat. Eurostat regional yearbook 2013, Office of the European Union, Luxembourg, 250-252, 2013.

[19] European Commission, Directorate-General for Economic and Financial affairs. Five years of enlarged EU, Economic achievements and challenges, Bruxelles, 51-72, 2009.

[20] J. M. Wooldridge. Introductory Econometrics, a modern approach, $5^{\circ}$ Edition, South-Western Cengage Learning, Mason (USA), 168-185, 2012.

[21] European Commission. Commission Staff Working Document, Montenegro 2013 Progress Report, accompanying the document «Communication from the Commission to the European Parliament and the Council», Bruxelles, 56-58, 2013.

[22] European Commission. Commission Staff Working Document, Serbia 2013 Progress Report, accompanying the document "Communication from the Commission to the European Parliament and the Council», Bruxelles, 62-64, 2013.

[23] European Commission. Commission Staff Working Document, The former Yugoslav Republic of Macedonia 2013 Progress Report, accompanying the document "Communication from the Commission to the European Parliament and the Council», Bruxelles, 60-62, 2013.

[24] European Commission. Commission Staff Working Document, Albania 2013 Progress Report, accompanying the document «Communication from the Commission to the European Parliament and the Council», Bruxelles, 59-61, 2013.

[25] European Commission. Commission Staff Working Document, Bosnia and Herzegovina 2013 Progress Report, accompanying the document «Communication from the Commission to the European Parliament and the Council», Bruxelles, 56-58, 2013.

[26] European Commission. Commission Staff Working Document, Kosovo 2013 Progress Report, accompanying the document "Communication from the Commission to the European Parliament and the Council», Bruxelles, 53-55, 2013.

[27] European Commission. Commission Staff Working Document, Turkey 2013 Progress Report, accompanying the document «Communication from the Commission to the European Parliament and the Council», Bruxelles, 78-80, 2013. 